\title{
¿UNA ESTRATEGIA COHERENTE PARA UNA REGIÓN EN CAMBIO? LA POLÍTICA EXTERIOR DE LA ADMINISTRACIÓN OBAMA Y LA PRIMAVERA ÁRABE
}

\author{
Juan Tovar Ruiz ${ }^{1}$ \\ Universidad de Burgos/Universidad Autónoma de Madrid
}

\begin{abstract}
Resumen:
La política exterior de la Administración Obama se vio claramente marcada por los procesos de cambios producidos en el Próximo Oriente como consecuencia de la denominada Primavera Árabe. A la discusión previa existente sobre la existencia o no de una doctrina Obama se ha añadido el debate sobre cual puede ser su estrategia hacia una región que se ha convertido en el principal campo de batalla de los grupos ideológicos de la política exterior estadounidense: realistas, neoconservadores y liberales intervencionistas. La necesidad de equilibrar los intereses estratégicos y de seguridad estadounidenses con la promoción de valores como la democracia y los derechos humanos parece haber dado paso a un regreso a una estrategia realista, de intervención limitada, fundamentada en intereses estratégicos clave y en soluciones diferenciadas para diferentes contextos. La situación actual en escenarios como Siria o Irak, con todo, marcan importantes incertidumbres que deberán ser afrontadas a corto plazo.
\end{abstract}

Palabras clave: Política exterior, Primavera Árabe, doctrina, ideología, democracia, intereses estratégicos.

Title in English: "A Coherent Strategy for a Changing Region?: The Obama Administration Foreign Policy and the "Arab Spring".

\section{Abstract:}

The Foreign Policy of the Obama Administration has been clearly affected by the process of change in the Middle East known as Arab Spring. The debate about the nature of the Strategy of the president for that region has been added to the previous debate about the mere existence of an Obama doctrine, as the region has turned to be the main battlefield of the ideological groups of the American Foreign Policy: realists, neoconservatives and liberal interventionists. The need of balancing the strategic and security interest with the promotion of values such as the liberal democracy or the human rights has been followed by some kind of return to a realist strategy, of limited intervention, founded in core strategic interests and different solutions for different contexts. The contemporary conflict in states like Iraq or Syria, presents enormous uncertainties which should be confronted in the short term.

Keywords: Foreign Policy, Arab Spring, doctrine, ideology, democracy, strategic interests.

Copyright $\odot$ UNISCI, 2014.

Las opiniones expresadas en estos artículos son propias de sus autores, y no reflejan necesariamente la opinión de UNISCI. The views expressed in these articles are those of the authors, and do not necessarily reflect the views of UNISCI

\footnotetext{
${ }^{1}$ Juan Tovar es profesor ayudante doctor en la Universidad de Burgos y honorario en la Autónoma de Madrid. Sus líneas de investigación abarcan, entre otras, el análisis de la política exterior estadounidense, las relaciones transatlánticas o la política exterior española.

E-mail: juan.tovar@uam.es.
} 


\section{Introducción}

El día 4 de junio del año 2009, el presidente estadounidense Barack Obama lanzaba un esperado discurso destinado a fomentar la reconciliación entre Estados Unidos, embarcado desde el 11 de Septiembre del año 2001 en la Guerra contra el Terror, y el mundo árabe. En dicho discurso el presidente estadounidense retomaba el camino iniciado en su discurso inaugural de enero de ese mismo año, donde planteaba alargar el brazo si los enemigos de Estados Unidos "estuviesen dispuestos a abrir el puño", rechazando la posibilidad de nuevos cambios de régimen, tal y como los defensores del realismo político, dentro y fuera de su Administración habían estado defendiendo tras la Guerra de Irak. Dos años después, el 19 de mayo de 2011 y tras los cambios producidos en Túnez, Egipto y una intervención militar en Libia, el presidente estadounidense saludaba los procesos de cambio en un momento de clara incertidumbre sobre su resultado. Entre los años 2013 y 2014, sin embargo, en los discursos ante la Asamblea General de Naciones Unidas o West Point, el discurso pone como elemento central de la política exterior en Estados Unidos una serie de elementos centrales de seguridad como la lucha antiterrorista, evitar agresiones externas o la proliferación de armas de destrucción masiva.

Viendo estos sucesos cabe preguntarse acerca de las causas de este cambio, más o menos profundo, de la política exterior estadounidense respecto de lo inicialmente planteado respecto de la región de Próximo Oriente y Norte de África, además de la coherencia o no estratégica del mismo y la situación en que la posición geopolítica estadounidense ha quedado, además de sus importantes consecuencias en el debate de los grupos ideológicos presentes en la política exterior estadounidense. Este es el objetivo del presente artículo.

\section{Marco teórico}

Tal y como se ha explicado, la presente investigación trata el rol de la política exterior estadounidense en el seno de los cambios producidos en el Norte de África y el Próximo Oriente. Para ello se utilizarán diferentes fuentes tanto de carácter primario como secundario, entre las primeras cabe destacar los discursos del presidente Obama, las Estrategias de Seguridad Nacional de las diferentes Administraciones Estadounidenses y las doctrinas formuladas sucesivamente por los presidentes americanos. A estas fuentes cabe añadir aquellas de carácter secundario, tanto artículos como monografías, elaboradas por expertos en la materia, así como por aquellos que han estado en contacto con destacados miembros de la Administración Obama y recogido los diferentes procesos que llevaron a la toma de decisiones y a la conformación de su propia acción política. Todo ello permitirá iluminar las intenciones y objetivos principales que dicha Administración ha tenido a la hora de acometer sus acciones.

En lo que respecta al marco teórico, la presente investigación tiene un carácter abierto, teniendo en cuenta las importantes limitaciones de las diferentes teorías de las relaciones internacionales a la hora de explicar una realidad compleja. De tal forma, se utilizarán elementos de dichas teorías y, principalmente de carácter realista y constructivista. Del realismo político se tomará la importancia de los elementos materiales y de las cuestiones de poder a la hora de entender el comportamiento de los principales actores, así como la naturaleza principal del Estado como actor de las relaciones internacionales en el marco de la competición por la hegemonía en la región. La acumulación de poder, a efectos de garantizar la propia supervivencia, es uno de los factores más importantes a tener en cuenta y uno de los 
motores del comportamiento de los actores en el sistema internacional. ${ }^{2}$ Es también destacable, a efectos de este trabajo, la relevancia de ver "no solo de lo que se dice, sino también de lo que se hace" tal y como autores como George F. Kennan han estado destacando a lo largo del tiempo. ${ }^{3}$

Sin embargo, este no es un trabajo únicamente fundamentado en cuestiones materiales, de tal forma el análisis del discurso será uno de los factores fundamentales recogidos en el mismo -si bien matizado y limitado por las propias realidades materiales y del poder-. La importancia de las percepciones, de la transformación de realidades, de las identidades y de la interacción de los actores también tiene su papel aquí, dándole un cierto valor a perspectivas constructivistas moderadas, que no nieguen la validez de argumentos que reconozcan la existencia de una cierta realidad objetiva susceptible de analizar. ${ }^{4}$

Finalmente pero no menos importante cabe añadir los elementos relacionados con el denominado análisis de política exterior, fundamental en un trabajo de este tipo a la hora de analizar la política exterior de Estados Unidos. Desde esta perspectiva cabe recoger los diferentes elementos que haría que este análisis fuese, dentro de las lógicas limitaciones materiales y de espacio, lo suficientemente complejo. En este sentido destacan diferentes elementos como las percepciones de los principales actores en la toma de decisiones de la política exterior estadounidense, sus convicciones ideológicas, sus identidades, sus objetivos, su posición de poder y otra serie de importantes circunstancias que permiten moldearla a estos efectos.

Dentro de la política exterior estadounidense cabe destacar algunos de sus aspectos concretos que tendrán incidencia en el presente trabajo. Entre ellos sus órganos de toma de decisiones, el poder y la influencia del presidente en cuestiones militares y de política exterior, las competencias del Congreso estadounidense imponiendo sanciones o ratificando tratados, el posicionamiento de las diferentes agencias y Departamentos como el Departamento de Estado en lo que respecta a la diplomacia, el Pentágono y la Junta de Jefes de Estado Mayor en las cuestiones militares, la labor de coordinación del Consejo de Seguridad Nacional en cuestiones de seguridad o el rol de think tanks y grupos de interés privado como la famosa AIPAC. Todo ello permitirá articular la política exterior de Estados Unidos y los intentos de conseguir el cumplimiento de los objetivos planteados. ${ }^{5}$

Además son de destacar las diferentes corrientes de su política exterior, que autores como Walter Russell Mead, identificaron y dividieron en cuatro distintas utilizando los nombres de presidentes estadounidenses históricos. Entre ellas el nacionalismo jacksoniano de las comunidades rurales estadounidenses, el prudente liberalismo jeffersoniano, el realismo anglosajón hamiltoniano fundamentado en la defensa de intereses comerciales o el famoso idealismo wilsoniano con su idea de "hacer el mundo seguro para la democracia". 6

Estos elementos propios del sistema político estadounidense han de acompañarse con la presencia de grupos ideológicos que conforman las elites de la política exterior de Estados Unidos. En este sentido, en el debate estadounidense sobre el Próximo Oriente cabe destacar la presencia de las tres principales: los realistas, defensores de una política exterior orientada a

\footnotetext{
${ }^{2}$ Mearsheimer, John J. (2001): The Tragedy of Great Power Politics, Nueva York, Norton \& Co., pp. 1-54.

${ }^{3}$ Kennan, George F: "Morality and Foreign Policy", Foreign Affairs, vol. 64, no 2 (invierno 1985).

${ }^{4}$ Wendt, A: "Anarchy is What States Make of It: The Social Construction of Power Politics", International Organization, vol. 46, n 2 (1992), pp. 391-425.

${ }^{5}$ Neustadt, Richard E. (1990): Presidential Power and the Modern Presidents. The Politics of Leadership from Roosevelt to Reagan, Nueva York, Free Press, pp. 29-49. Brown, Eugene y Snow, Donald M. (2000): United States Foreign Policy. Politics Beyond the Water's Edge, Boston, Bedford/St. Martin's, pp. 95-271.

${ }^{6}$ Mead, Walter R. (2002): Special Providence. American Foreign Policy and How it Changed the World, Nueva York, Routledge, pp. 1-29.
} 
la defensa de intereses nacionales establecidos sobre la base de la seguridad y de la utilización del equilibrio de poderes como un instrumento para mantener el statu quo -herederos de la corriente que estadistas e intelectuales como Kennan o Kissinger utilizaron durante la Guerra Fría-. Los liberales intervencionistas, herederos de la tradición wilsoniana de política exterior basada en la relevancia de las instituciones internacionales y la expansión de la democracia liberal como forma de gobierno, con destacadas figuras como Susan Rice o Samantha Power. Finalmente estarían los neoconservadores, partidarios del unilateralismo y el uso de la fuerza a efectos de extender la forma de gobierno y los valores estadounidenses. Estos dos últimos grupos comparten un posicionamiento común frente a los realistas del Partido Demócrata o Republicano asentado sobre las bases de la defensa de la idea de la responsabilidad de proteger, la relevancia de la famosa teoría de la paz democrática y de Estados Unidos como la "nación indispensable". 7

Estos grupos ideológicos y sus principales representantes serán fundamentales a la hora de entender las dinámicas y debates producidos en la política exterior de Estados Unidos durante los complejos procesos de cambio que se van a producir en este periodo, en los que realistas y liberales intervencionistas o neoconservadores van a verse inmersos, con casos enormemente destacados como los de Libia o Siria e incluso sobre la propia relevancia de la misma. Es necesario, en cualquier caso, para comprender el posicionamiento de la Administración Obama, plantear una breve introducción histórica de las relaciones entre Estados Unidos y la región a tratar.

\section{La herencia histórica de la Administración Obama: las relaciones entre Estados Unidos v el Próximo Oriente}

Si bien la presencia diplomática de Estados Unidos en el Norte de África y Próximo Oriente se remonta a tiempos bastante anteriores, a destacar etapas como la de Theodore Roosevelt en relación a las crisis marroquíes, para considerar dicha región como geopolíticamente central o prioritaria hemos de remontarnos a la etapa de la Guerra Fría y, concretamente, a las doctrinas de Eisenhower, Nixon y Carter. No obstante ya estuvo presente en la política exterior estadounidense de la época, desde la asistencia del presidente Truman al gobierno turco en los años 40. En los años 50 destacarían el famoso golpe de Estado que se produciría en Irán contra el primer ministro Mossadeq o la formulación de la doctrina Eisenhower a raíz de los eventos acaecidos en la Crisis de Suez de 1956 que acabaría incorporando el Próximo Oriente a las prioridades estratégicas de la política de contención estadounidense del comunismo ${ }^{8}$. En el caso de la doctrina Nixon, el Próximo Oriente se integraría dentro de la estrategia de equilibrios de poder regionales que sustentaban el equilibrio de poderes global y el statu quo frente a la URSS, con Irán o Arabia Saudita como algunos de sus pilares centrales. ${ }^{9}$ La presencia de aliados soviéticos en la región, convirtió a algunos de estos Estados en actores centrales de la estrategia estadounidense formulada, en la que la contención del comunismo se vería favorecida por la ayuda estadounidense a sus aliados como se realizó en Asia tras el conflicto de Vietnam, dada la naturaleza propia de la doctrina Nixon de ayudar a los aliados y

\footnotetext{
${ }^{7}$ Smith, Tony: "Wilsonianism after Iraq", en Ikenberry, John G. (ed.) (2008): The Crisis of American Foreign Policy. Wilsonianism in the Twenty-first Century, Princeton, Princeton University Press, pp. 66-74.

${ }^{8}$ Véase el famoso discurso del presidente Truman del 12 de marzo de 1947, que inaugural la doctrina que lleva su nombre, en http://avalon.law.yale.edu/20th_century/trudoc.asp En el caso de la formulación de la doctrina Eisenhower, en http://www.presidency.ucsb.edu/ws/index.php?pid=11007\&st=\&st1.

${ }^{9}$ Ravenal, Earl C. (1989): Large-Scale Foreign Policy Change: The Nixon Doctrine as History and Portent, Berkeley University of California, Institute of International Studies, pp. 15-64.
} 
no de combatir por ellos. ${ }^{10}$ Asimismo, eventos que se desarrollaban en aquel periodo, como la guerra del Yom Kippur, fueron esenciales en el fracaso de la doctrina defendida por Nixon, Ford y Kissinger. ${ }^{11}$

Esta importancia se incrementaría con la doctrina Carter, formulada a raíz de la intervención soviética en Afganistán y de los temores suscitados por la caída del régimen del sha en Irán. En dicha doctrina se establecía que "cualquier potencia foránea que pretendiese controlar la región del Golfo Pérsico sería considerada una amenaza para los intereses vitales estadounidenses y repelida por todos los medios posibles, incluyendo el de la fuerza militar". ${ }^{12}$ La asistencia estadounidense en Afganistán y la consiguiente política del presidente Reagan hacia Irak e Irán, así como una gran pluralidad de intereses que irían desde la seguridad, el mantenimiento del statu quo, o la relevancia energética de la región se irían combinando a lo largo del tiempo. Con el presidente Bush padre y la famosa Guerra del Golfo, esta relevancia continuaría. El establecimiento de la gran coalición para expulsar a las tropas iraquíes del emirato de Kuwait se convirtió en la aplicación más destacada de una Administración que, en los últimos momentos de la Guerra Fría, pretendió hacer del multilateralismo o Naciones Unidas uno de los ejes de su política internacional y de su conocida doctrina del Nuevo Orden Mundial. Entre las razones de este conflicto destacarían el mantenimiento del statu quo regional o el impedir que Shaddam se hiciese con el $20 \%$ de las reservas de petróleo mundiales, además del cumplimiento de las normas internacionales. En este sentido, la polémica decisión tomada por la Administración de dejar que Shaddam Hussein permaneciese en el poder y no provocar un cambio de régimen, sería otro de los factores que permitirían plantear la continuidad de la relevancia de la región en el debate político estadounidense junto con los intentos por revitalizar el estancado proceso de paz en Oriente Próximo. ${ }^{13}$

El fin de la Guerra Fría no traería consigo el fin del protagonismo de esta región en la política exterior estadounidense. Durante la Administración Clinton, la expansión de la democracia se había convertido en uno de los factores centrales de su política exterior como tercer pilar, tal y como se recoge en su doctrina y discursos ${ }^{14} \mathrm{o}$ en sus intervenciones e intentos de construcción de democracias en Haití o los Balcanes. A esto no sería ajeno que el fin de la Guerra Fría trajo el fin del predominio exclusivo del realismo político en la política internacional estadounidense y el desarrollo de teorías rivales como la famosa tesis de la paz democrática, que plantea que las democracias liberales nunca o casi nunca se hacen la guerra entre ellas o la revitalización de corrientes como el idealismo wilsoniano y su idea de "hacer el mundo seguro para la democracia", que sería reivindicado por nuevos grupos ideológicos como los liberales intervencionistas del Partido Demócrata o los neoconservadores de tercera generación. ${ }^{15}$

\footnotetext{
${ }^{10}$ En este sentido cabe destacar el famoso discurso del presidente Nixon, en relación a la" vietnamización" de 3 de noviembre de 1969. http://www.presidency.ucsb.edu/ws/?pid=2303

${ }^{11}$ Litwack, Robert S. (1984): Détente and the Nixon Doctrine. American Foreign Policy and the Pursuit of Stability, Cambridge, Cambridge University Press, p. 158.

12 Véase el famoso discurso del Estado de la Unión de 1980 del presidente Carter http://www.jimmycarterlibrary.gov/documents/speeches/su80jec.phtml

${ }^{13}$ Haass, Richard N. (2010): War of Necessity, War of Choice. A Memoir of two Iraq Wars, Nueva York, Simon and Schuster Paperbacks, pp. 17-59. Bush, George H. W. y Scowcroft, Brent (1998): A World Transformed, Nueva York, Vintage Books, pp. 302-333.

${ }^{14}$ Véase el discurso de 1993 del Consejero de Seguridad Nacional Anthony Lake en la Universidad John Hopkins, en https://www.mtholyoke.edu/acad/intrel/lakedoc.html o los propios discursos del presidente como el del Estado de la Unión de 1994, en

http://www.washingtonpost.com/wp-srv/politics/special/states/docs/sou94.htm y la propuesta de su secretaria de Estado Madeleine Albright de crear una Comunidad de Democracias.

${ }^{15}$ Smith, Tony: "Democratic Peace Theory: From Promising Theory to Dangerous Practice", International Relations, vol. 25, $\mathrm{n}^{\circ} 2$ (2011), pp. 151-154. Smith, op.cit. Vaisse, Justin (2010): Neoconservatism. The
} 
La importancia creciente de la lucha frente al terrorismo y de de Osama Ben Laden, a raíz de los ataques estadounidenses en Sudán y Afganistán o el creciente debate sobre el cumplimiento de las resoluciones de Naciones Unidas en relación a su desarme por Shaddam Hussein, se fue incrementando. También las consiguientes presiones de grupos como los neoconservadores, algunos de cuyos representantes como Wolfowitz o, figuras políticas no demasiado lejanas como Cheney, defendían que no haberle derribado tras la Guerra del Golfo había resultado una equivocación ${ }^{16}$-aún cuando no hay constancia de que dichos autores se opusiesen a la decisión tomada en su momento pese al posterior cambio de opinión o que los argumentos de Bush padre y Scowcroft para no hacerlo, a la postre, resultasen acertados-. No es ningún secreto, que el debate principal sobre la Guerra de Irak se produciría, precisamente, entre algunos de los principales protagonistas de la antigua Guerra del Golfo como Cheney, Powell, Scowcroft o Wolfowitz y dentro del propio Partido Republicano. ${ }^{17}$

Los atentados del 11 de Septiembre situaron al Próximo Oriente en un lugar central para la política exterior estadounidense, como nunca lo había estado en el pasado. El desencadenamiento de las intervenciones en Afganistán o Irak, así como de la denominada "Guerra global contra el terror", acabaron condensando una gran pluralidad de intereses que venían existiendo hasta ese momento, desde la defensa de la seguridad estadounidense frente a ataques terroristas hasta la expansión de la democracia liberal como receta frente a la violencia y el terrorismo, en una velada acusación hacia las autocracias que componían, supuestamente, aquel monolítico bloque que hacía imposible la realización de una población oprimida y desesperada que no vería más opción que entregarse a este tipo de lucha. Estrategias como la famosa Freedom Agenda tienen su origen en esta política. Esta gran pluralidad de intereses e ideales quedarían reflejadas en las famosas Estrategias de Seguridad Nacional de los años 2002 y 2006, así como en numerosos discursos del presidente estadounidense $^{18} \mathrm{o}$, en los dos grandes procesos de construcción estatal iniciados en Afganistán e Irak que resultarían, a la postre, en un rotundo fracaso que incrementaría el pesimismo sobre las posibilidades de exportar la democracia. ${ }^{19}$ De igual forma, determinadas prácticas como la tortura, los vuelos secretos o la prisión de Guantánamo erosionaban la imagen de Estados Unidos en el mundo y perjudicaba el objetivo de extender la democracia, como lo demostraron los casos de Líbano, Egipto o cualquier revitalización del proceso de paz entre israelíes y palestinos. Los debates continuados de Estados Unidos con algunos de sus aliados tradicionales como Francia o Alemania, entre grupos ideológicos como realistas y neoconservadores y la pérdida de imagen por lo que parte de la opinión pública global

Biography of a Movement, Cambridge Massachussets, Harvard University Press, pp. 277-279. Tovar, Juan (2014): La política exterior de Estados Unidos y la expansión de la democracia (1989-2009), Valencia, Tirant lo Blanch, pp. 345-368.

${ }^{16}$ Packer, George (2005): The Assassin's Gate. America in Iraq, Nueva York, Farrar Strauss and Giroux, pp. 2060.

${ }^{17}$ Mann, James (2004): The Rise of the Vulcans. The History of Bush War's Cabinet, Nueva York, Penguin Books, pp. 342-344.

${ }^{18}$ Véanse por ejemplo http://georgewbush-whitehouse.archives.gov/nsc/nss/2002/ o

http://georgewbush-whitehouse.archives.gov/nsc/nss/2006/index.html así como discursos como el inaugural de su segundo mandato http://www.nytimes.com/2005/01/20/politics/20BUSH-TEXT.html? r=0 o los que lanzaría ante la famosa organización National Endowment for Democracy en 2002 o 2003.

${ }^{19}$ Diamond, Larry (2008): The Spirit of Democracy. The Struggle to Build Free Societies Through the World, Nueva York, Holt Paperbacks, pp. 12-15. Barany, Zoltan; Moser, Robert G. (eds.) (2009): Is Democracy Exportable?, Cambridge, Cambridge University Press, pp. 242-264. 
consideraba una guerra "ilegal", dio lugar a toda clase de teorías conspirativas sobre las intenciones americanas. $^{20}$

Estas teorías fueron favorecidas por la imposibilidad de hallar las armas de destrucción masiva que sirvieron como justificación inicial, aunque no única ni necesariamente la más importante, como las palabras de autores o políticos con posicionamientos tan distintos como el Baradei o Wolfowitz han puesto de manifiesto y cuya supuesta existencia el propio Shaddam no negó de manera tajante por el temor a sus enemigos internos o regionales. ${ }^{21} \mathrm{La}$ brutal pérdida de imagen o poder blando por parte de Estados Unidos será una de las razones principales de un fracaso determinado en mayor medida por la incapacidad -o imposibilidadde llevar a cabo con éxito dos carísimos procesos de nation-building, que trajeron como resultado más de un billón de dólares en gasto, 4.000 vidas de militares estadounidenses pérdidas o 100.000 iraquíes mientras la situación afgana empeoraba. ${ }^{22}$

La impopularidad del conflicto llegó a tal nivel que el propio presidente Bush, después del relativo éxito de la estrategia contrainsurgente de Petraeus, el tan dilatado aumento de tropas -favorecido por la llegada a la secretaría de Defensa de Robert Gates y el fin de la estrategia de Rumsfeld de un ejército pequeño, mortífero y tecnológicamente bien equipado- ${ }^{23}$ y la alianza con las tribus suníes, decidió en plena campaña presidencial comenzar la retirada de tropas estadounidenses de Irak. ${ }^{24}$

\section{4. ¿Un retorno al realismo? La elección de Barack Obama y la aparición de una nueva estrategia para el Próximo Oriente}

Estas decisiones, así como el conflicto que estallaría en septiembre de 2008 en Georgia, no evitarían la victoria de Obama frente a un senador McCain que se vio perjudicado por la impopularidad de la Administración Bush y que mantenía algunos de los postulados defendidos por destacados autores neoconservadores como su asesor, Robert Kagan, a destacar la famosa propuesta de la creación de una Liga de democracias. ${ }^{25}$

El propio candidato Obama y prácticamente desde un principio quiso distanciarse de la política defendida por su predecesor, particularmente en lo que respecta a la imposición de la democracia liberal mediante el uso de la fuerza, como había sucedido en Afganistán e Irak. Si uno lee algunos de los discursos electorales utilizados, la búsqueda de una cierta conciliación con los adversarios de Estados Unidos, la mayor relevancia concedida a la región de AsiaPacífico, el rechazo a la imposición de la democracia liberal por la fuerza y el fortalecimiento del proceso de paz en Oriente Próximo fueron algunos de los ejes principales de su discurso en política internacional junto con determinados desafíos transnacionales como la lucha

\footnotetext{
${ }^{20}$ Nye, Joseph (2004): Soft Power. The Means to Success in World Politics, Nueva York, Public Affairs, pp. ixxiii y 127-148. Traub, James (2008): The Freedom Agenda: Why America Must Spread Democracy —Just not the Way George Bush Did-, Nueva York, Farrar, Straus and Giroux, pp. 123-137.

${ }^{21}$ El Baradei, Mohammed (2011): Años de impostura y engaño. La diplomacia nuclear en tiempos difíciles, Barcelona, RBA, pp. 59-99. Gordon, Michael R. y Trainor, Bernard E. (2006): COBRA II. The Inside Story of the Invasion and Occupation of Iraq, Nueva York, Vintage Books, ps. 73-76. Gray, John (2006): Contra el progreso y otras ilusiones, Barcelona, Paidós, pp. 155-171.

${ }_{22}$ Brzezinski, Zbigniew (2007): Second Chance. Three Presidents and the Crisis of American Superpower, Nueva York, Basic Books, p. 148.

${ }^{23}$ Shimko, Keith L. (2010): The Iraq Wars and America's Military Revolution, Cambridge, Cambridge University Press, pp. 213-237.

24 "Bush anuncia la retirada de tropas de Irak, pero mandará más efectivos a Afganistán”, El Mundo, 9 de septiembre de 2008.

${ }^{25}$ McCain, John: “An Enduring Peace Built on Freedom”, Foreign Affairs, vol. 86, n’ 6 (noviembre/diciembre 2007).
} 
contra el cambio climático o la desnuclearización. En lo que respecta al Próximo Oriente, este discurso reconoce la necesidad de pasar página en la Guerra de Irak, desarrollando una estrategia más cercana a un cierto multilateralismo que refuerce las alianzas, permita llevar a buen puerto el proceso de paz en Oriente Próximo e incluso negociar directamente con Irán o Siria sin descartar una posible opción militar para evitar que el primero continúe con su plan nuclear y el segundo siga apoyando movimientos terroristas como Hamás o Hezbollá. De igual manera, se mantenía la necesidad de combatir a al-Qaeda y evitar que adquiera "santuarios" o armas de destrucción masiva, si bien relacionándolo en mayor medida con Afganistán y Pakistán ${ }^{26}$. También son de destacar sus elogios a algunas figuras muy concretas de la política estadounidense a nivel teórico o práctico como Reinhold Niehbur, Harry Truman, Brent Scowcroft o Bush padre, identificados generalmente con el realismo político en relaciones internacionales. ${ }^{27}$

La actitud más conciliadora de Obama podía observarse también en su discurso inaugural como presidente de 20 de enero de 2009, donde plantea la posibilidad de "alargar el brazo si están dispuestos a abrir el puño" en clara referencia a los adversarios autocráticos de Estados Unidos. ${ }^{28}$ Contra lo que algunos autores han venido planteando, los derechos humanos y la expansión de la democracia liberal quedaron relativamente fuera de la agenda principal estadounidense, tal y como recogen las propias palabras de la secretaria de Estado Hillary Clinton en relación a China. ${ }^{29}$ Una actitud más dialogante con sus adversarios, así como la aparición de nuevos desafíos transnacionales en la agenda como la cuestión del cambio climático, la desnuclearización o los desafíos de la crisis económica en las famosas reuniones del G-20, irían cobrando protagonismo a lo largo del tiempo. ${ }^{30}$

El gabinete que el presidente Obama conformaría en este primer mandato ayuda a entender algunas de sus principales decisiones en política internacional, que parece mantener un cierto equilibrio entre algunas de las ideologías clave de la política exterior de Estados Unidos y una cierta continuidad con su predecesor. De hecho, el mantenimiento de Robert Gates como secretario de Defensa - muy vinculado a la corriente del realismo político republicano que se relaciona con Kissinger, Scowcroft y Bush padre- es el mejor ejemplo. La incorporación de Hillary Clinton, con quien haría tándem habitualmente este último, pese a permanecer lejos del círculo principal de asesores jóvenes del presidente, les permitiría ser más influyentes de lo habitual. El vicepresidente Biden participaría en algunos de los principales debates de política internacional dado su conocimiento de la misma. Susan Rice, discípula de Madeleine Albright y defensora de intervenciones fundamentadas en ideales como los derechos humanos, también tendrá un rol importante desde su puesto como embajadora en Naciones Unidos. Finalmente, los miembros más entusiastas del presidente y, quizá los de mayor confianza, eran su círculo de asesores más jóvenes que Mann define como los Obamians y que agrupan desde Samantha Power, autora del discurso del premio nobel y una conocida periodista, académica y activista de los derechos humanos -representante destacada de los "liberales intervencionistas"-a Dennis McFaul, Ben Rhodes, su speechwritter, y el viceconsejero y luego consejero de Seguridad Nacional Tom Donilon, partidario de una visión realista de las relaciones internacionales. James Jones, el primer consejero de Seguridad Nacional y antiguo Comandante Supremo de las Fuerzas Aliadas para Europa, fue siempre un outsider y dejaría eventualmente su puesto, al igual que militares

\footnotetext{
${ }^{26}$ Obama, Barack:“Renewing American Leadership”, Foreign Affairs, vol. 86, no 4 (julio/agosto 2007).

${ }^{27}$ Brooks, David: "Obama, Gospel and Verse", The New York Times, 26 de abril de 2007.

${ }^{28} \mathrm{http}: / /$ www.america.gov/st/usg-english/2009/January/20090120130302abretnuh0.2991602.html

29 "Hillary Clinton habla con China de economía, DDHH quedan en segundo plano", AFP, 22 de noviembre de 2009.

${ }^{30}$ Tovar, Juan: "El enigma de la doctrina Obama. Un año de política exterior norteamericana", Real Instituto Elcano, DT no 2/2010 (febrero).
} 
destacados e influyentes como McChrystal o Petraeus, afectados por diferentes escándalos. En las memorias de Gates, publicadas recientemente, se han desvelado algunas de las claves que permiten dilucidar los desacuerdos producidos en el primer mandato de Obama. De tal forma, los desacuerdos y enfrentamientos entre el secretario de Defensa y el vicepresidente Biden, particularmente en torno a la cuestión afgana, han sido remarcados por Gates. Estos desacuerdos se irían modificando a lo largo del tiempo y ambos decisores acabarían en el mismo bando cuando la Primavera Árabe estallase frente a los asesores jóvenes del presidente. $^{31}$

La mayor parte de asesores jóvenes eran, originalmente, partidarios de una visión del mundo, que se orientaba más a Asia y las potencias emergentes que a la tradicional visión transatlántica de las elites estadounidenses como demostraron en la Cumbre de Copenhague, cuando Estados Unidos apoyó a las potencias emergentes frente a sus aliados europeos. De igual forma, no todos fueron partidarios de una visión realista de las relaciones internacionales donde los elementos ideológicos quedasen en segundo plano, pero las preferencias del propio Obama, que a menudo se alineaba con Gates, Donilon o Brennan a la hora de tomar una decisión frente a la postura de los liberales intervencionistas, hizo que la mayor parte de la política exterior de su primer mandato se orientase más a los presupuestos de esta escuela de pensamiento con alguna excepción relevante como sería el caso de Libia. ${ }^{32}$ De hecho, y aún siendo escrito por la propia Power, el discurso del premio Nobel importa algunos de los principales conceptos elaborados por autores realistas tan destacados como Richard Haass, al identificar la Guerra de Afganistán como una "guerra de necesidad" y compararla con la de Irak, una "guerra de elección". 33

En lo que respecta a la región del Próximo Oriente, la actitud conciliadora del presidente estadounidense se plasmaría en su discurso más famoso de esta primera etapa como fue el famoso discurso de El Cairo de 4 de junio de 2009. Teniendo en cuenta el desgaste de popularidad en la región, la herencia recibida de la Administración Bush tanto en lo que respecta a la famosa "Guerra contra el terror" como a la Freedom Agenda, dicho discurso se veía aún más necesario por la necesidad de "reconciliar" al Islam con Estados Unidos. $^{34}$

De hecho, el discurso de El Cairo va repasando cada una de las cuestiones que Estados Unidos tenía pendientes con la región, desde la compatibilidad del Islam con la democracia o los derechos humanos hasta el plan nuclear iraní, la lucha contra el terrorismo, el proceso de paz en Oriente Próximo - al que dedica una parte importante del discurso- o a los conflictos que aún mantenía vivos en Afganistán e Irak, dejando claro que Estados Unidos, aunque considera la democracia compatible con el Islam, no impondrá forma de gobierno alguna mediante el uso de la fuerza. Reconociendo dicha relación con el conflicto iraquí.

Poner fin a ese conflicto y retirar las tropas estadounidenses se convirtió en uno de sus principales objetivos, que se acometería definitivamente durante el verano de 2010 y culminaría con la retirada de sus soldados en diciembre de 2011. ${ }^{35}$ Entretanto, la situación en Afganistán hacía que la Administración se centrase, principalmente, en dicho conflicto. Esto

\footnotetext{
${ }^{31}$ Gates, Robert (2014): Duty. Memoirs of a Secretary at War, Nueva York, Alfred A. Knopf, pp. 283, 335-386 y 502-506. Clinton, Hillary (2014): Hard Choices, Nueva York, Simon \& Schuster, pp. 24-25. Mann, James (2012): The Obamians. The Struggle Inside the White House to Redefine American Power, Nueva York, Viking, pp. 1-12 y 211-228

Ibid., pp. 66-76 y 156-170.

${ }^{33} \mathrm{http}: / / \mathrm{www}$.whitehouse.gov/the-press-office/remarks-president-acceptance-nobel-peace-prize.

34 http://www.whitehouse.gov/the_press_office/Remarks-by-the-President-at-Cairo-University-6-04-09.

35 "Estados Unidos culmina su salida de Irak con la retirada de sus últimos soldados", El Mundo, 18 de diciembre de 2011.
} 
daría lugar a algunos de los debates internos más crudos que se producirían durante este primer mandato en el que Biden abogaba por un incremento de la estrategia de drones y fuerzas de inteligencia, el general Petraeus y McChrystal por un incremento notable de tropas, repitiendo la estrategia de contrainsurgencia ya utilizada en Irak y los secretarios de Estado y Defensa Clinton y Gates por un incremento más moderado de unos 30.000 soldados, que fue la decisión que se tomaría al final. La concentración en la defensa, la implicación de Pakistán y el rechazo a un costoso y largo proceso de "nation-building" tendente a establecer su democratización, sería algunos de los ejes de dicha estrategia que todavía se mantienen. ${ }^{36}$

El posicionamiento realista de la Administración Obama quedaría confirmado ante la relativa inacción producida por la misma en 2009, cuando a raíz de las elecciones iraníes, surge todo un movimiento de oposición a la victoria de Ahmadineyad denominado movimiento verde, que en algunos círculos de la política exterior de Washington se vio como un movimiento de cambio. La reacción del presidente Obama fue la de decir-probablemente no sin razón- que Musavi y Ahmadineyad "no son tan distintos". ${ }^{37}$ En el caso iraní, el presidente Obama y pese a alguna condena de la represión iraní, continuó inicialmente con la política de conciliación que le había llevado a felicitar el año nuevo persa en iraní y ofrecerse a un diálogo sobre asuntos como el plan nuclear, que no conduciría a resultados tangibles y le llevarían a una política más enérgica de establecimiento de sanciones al régimen. ${ }^{38}$ Muy distinta sería su actitud respecto de Libia.

La estrategia de los primeros años de su mandato, también queda reflejada en algunos de los documentos estratégicos más importantes de dicha Administración como la Estrategia de Seguridad Nacional del año 2010. En lo que respecta al Próximo Oriente, dicha estratégica concede una enorme importancia al mantenimiento de alianzas fuertes con sus aliados, mencionando específicamente Estados como Egipto, Jordania o los Estados de la Organización para la Cooperación en el Golfo Pérsico mientras se apoyaría a las organizaciones civiles que defienden la extensión de derechos a nivel universal en una defensa de cierto multilateralismo. De igual manera el apoyo a la seguridad de Israel y su derecho a existir se mantiene como un objetivo clave. La retirada de Irak y la necesidad de combatir a al-Qaeda son también mencionados como objetivos prioritarios. En este último caso se plantearía como objetivo la necesidad de evitar que pudiese tener un "santuario", prevenir la posibilidad de ataques en suelo estadounidense y de que adquiriese armas de destrucción masiva, dejando claro que no se está mencionando en ningún momento una posible guerra contra el Islam, sino contra una red terrorista. Es interesante observar los elementos jeffersonianos de dicha estrategia, cuando se menciona respecto de la cuestión de valores e ideales la necesidad de "predicar con el poder de nuestro ejemplo" antes que usar la fuerza en defensa de los mismos y respetar el Estado de derecho. ${ }^{39}$

A pesar de las intenciones de la Administración Obama de llevar a cabo el famoso "giro hacia el Pacífico", ya demostrado por un acercamiento a las potencias emergentes no siempre exitoso, los acontecimientos de la Primavera Árabe impedirán que la potencia norteamericana se desentienda en mayor medida de los sucesos que se irían produciendo en la región. ${ }^{40} \mathrm{Ni}$

\footnotetext{
${ }^{36}$ Woodward, Bob (2010): Obama's Wars, Nueva York, Simon \& Schuster, pp. 34, 185-233, $246-256$ y $334-$ 380. Gates, op.cit., pp. 335-386. Clinton, op.cit., pp. 129-149.

37 "Obama minimiza la diferencia entre Musavi y Ahmadineyad”, El País, 17 de junio de 2009. "Obama quiere un nuevo comienzo en las relaciones con Irán”, El País, 20 de marzo de 2009.

38 "Obama quiere un nuevo comienzo en las relaciones con Irán”, El País, 20 de marzo de 2009. "EEUU aprueba imponer sanciones a las compañías que suministren gasolina a Irán”, $A B C, 17$ de diciembre de 2009.

${ }^{39}$ Véase http://www.whitehouse.gov/sites/default/files/rss_viewer/national_security_strategy.pdf

${ }^{40}$ Haass, Richard N.: "The Irony of American Strategy: Putting the Middle East in a Proper Perspective", Foreign Affairs, vol. 92, no 3 (mayo/junio 2013).
} 
siquiera la muerte de Ben Laden producida en $2011^{41}$, cuando la región entraba en un proceso de cambio incierto o su crecientemente independencia energética, impediría que Estados Unidos se viese involucrado en los convulsos acontecimientos que acontecían en el Norte de África y Oriente Próximo, acabando con las esperanzas de numerosos miembros de la Administración en este sentido.

\section{5. ¿Una estrategia coherente para una región en cambio? La Administración Obama y la Primavera Árabe}

El 19 de mayo de 2011, el presidente Obama daba en Washington, en la sede del Departamento de Estado, un discurso que resumiría y expresaría su visión sobre los acontecimientos que se habían producido en el Norte de África y Oriente Próximo, llevando la región a un cambio sin precedentes. ${ }^{42}$ Este discurso puede considerarse una segunda etapa en la política de la Administración Obama hacia la región, abiertamente distinta de la planteada en el famoso discurso de El Cairo de 2009.

El presidente Obama expone en dicho discurso algunos de los temas clave que centraron la política exterior estadounidense durante los años posteriores al 11 de Septiembre. Los conflictos de Irak y Afganistán y la muerte de Ben Laden, del que quiere rechazar toda idea de símbolo y afirma que es un "asesino en masa de musulmanes" son primeramente mencionados. A continuación recoge algunos hitos del proceso de cambio como la inmolación de Mohamed Bouazizi en Túnez y la consiguiente expansión de los movimientos de protesta. Expone su visión sobre el statu quo en la región, del que afirma "no es sostenible" y como durante tanto tiempo, la única libertad de expresión estaba relacionada con el comportamiento de Israel en relación a Palestina. Hace referencia a su discurso de El Cairo, cuando expresa la necesidad de compaginar la estabilidad de las naciones con la libertad individual.

Obama reconoce que los intereses a corto plazo no son compatibles muchas veces con las visiones a largo plazo. Tras hacer referencia a las transiciones egipcia y tunecina, menciona aquellos casos en los cuales la transición ha requerido del uso de la fuerza mencionando el caso libio en particular y la consiguiente intervención de la OTAN. De igual modo hacer referencia al caso sirio y considera que el presidente Asad tendría dos opciones, o liderar la transición o marcharse. Irán o las presiones realizadas para apartar al presidente yemení del poder también son mencionadas. Las contradicciones estadounidenses en su relación con el proceso de cambio son evidentes, incluyendo cierto doble rasero en el caso de Baréin, probablemente el más complicado por la dimensión de los intereses estadounidenses existentes en aquel Estado. De hecho, menciona que Irán "ha tratado de sacar provecho de la situación" y menciona "el legítimo interés" de la familia Al-Khalifa reintante, en garantizar el Estado de Derecho. De igual manera, el apoyo al proceso de paz en Oriente Próximo con el resultado de dos Estados que vivan en paz uno con otro y el reconocimiento del "derecho de Israel a su propia defensa" y su desconfianza en las negociaciones con grupos terroristas como Hamás que no reconocen su derecho a existir son combinadas. La igualdad de derechos entre hombres y mujeres, el apoyo a las transiciones y la necesidad de desarrollo económico también son mencionadas.

Este discurso es relevante por dos razones, en primer lugar porque expone una cierta creencia inicial en cierto relato optimista sobre la "Primavera Árabe" como cambio hacia un modelo positivo. En segundo lugar porque expone algunas de las contradicciones más

\footnotetext{
41 "Bin Laden is Dead, Obama says", The New York Times, 1 de mayo de 2011.

${ }^{42}$ Véase

http://www.whitehouse.gov/the-press-office/2011/05/19/remarks-president-middle-east-and-north-africa.
} 
importantes de la política exterior de Estados Unidos hacia estos procesos de cambio. ¿Por qué se actúa de manera distinta e incluso contradictoria en unos Estados y en otros? ¿Qué hace diferente a Túnez de Egipto, a Egipto de Baréin, a éste de Libia y a Siria de todos los anteriores?

El primero de los casos donde se ha producido cambio político y al que la mayor parte de los líderes de la Primavera Árabe consideran su modelo de éxito es el supuesto de Túnez. A diferencia de lo sucedido en otros casos, los intereses vitales estadounidenses en el Estado norteafricano no son elevados y el apoyo al proceso de transición que comenzó con la salida de Ben Alí del poder, se produjo rápido. De hecho, se condenó con bastante prontitud la represión que se venía ejerciendo por parte del gobierno ${ }^{43}$, en lo que algunos han considerado un éxito diplomático de la Administración, continuado a pesar de la subsiguiente relativa inestabilidad y de la victoria de los islamistas de Ennahada. El 7 de octubre de 2011, este apoyo y reconocimiento queda recogido en una entrevista conjunta que se realizaría tras la visita del primer ministro Essebsi a la Casa Blanca, en la que el presidente estadounidense reconocía los progresos de Túnez con la elaboración de la Constitución y la celebración de elecciones, además de la concesión de una ayuda económica simbólica de 39 millones de dólares y referencias al mutuo reconocimiento inicial como Estados independientes y soberanos en la primera visita del jefe de gobierno de un Estado afectado por el proceso de cambio. ${ }^{44}$

Muy distinto es el caso de Egipto. En este sentido la reacción estadounidense en un Estado cuya relevancia para el statu-quo regional es enorme, fue mucho más lenta que en el caso precedente. Mubarak había sido considerado un aliado desde hace mucho tiempo, con una participación destacada en el apoyo a Estados Unidos en conflictos como la Guerra del Golfo, además de tener el apoyo de aliados regionales tan relevantes como Arabia Saudita o Israel y un papel central en el proceso de paz en Oriente Próximo y en cuyo proceso de reforma y democratización George W. Bush había fracasado notoriamente. ${ }^{45}$

La cuantiosa ayuda ofrecida a su ejército anualmente tras la firma de los acuerdos de Camp David le ofrecía, sin embargo, una mayor capacidad de influencia que en otros supuestos. Las protestas masivas en la Plaza de Tahrir y la incapacidad del presidente egipcio para hacer frente a las protestas motivaría la decisión de apoyar su caída, no sin cierto debate e incluso oposición en la Administración y el Congreso Estadounidense. Si la intención había sido, originalmente, la tradicional defensa de derechos y libertades públicas sin pedir la salida del presidente egipcio; la cada vez más debilitada posición de Mubarak haría que el presidente Obama acabase apoyando su salida, llegando a solicitar el propio presidente Obama su renuncia en una conversación que mantuvieron cuando viajaba en el avión presidencial y el vicepresidente Biden haría lo mismo con el vicepresidente egipcio Suleiman. Todo ello con una intensa oposición de sus aliados saudíes que llegaron a reprocharle "abandonar a un amigo" tan antiguo y la preocupación de los israelíes por lo que pudiese suceder a continuación. ${ }^{46}$

Este proceso producido en tan solo diez días, queda reflejado en dos discursos del presidente estadounidense. El primero, de 1 de febrero de 2011, elogia al ejército, defiende las libertades y derechos que considera universales y reconoce tras una conversación con Mubarak la necesidad de cambios y la imposibilidad de mantener el statu quo, defendiendo la apertura de una transición y comunicando a los manifestantes que sus voces han sido oídas. El

\footnotetext{
${ }^{43}$ Véase http://www.whitehouse.gov/the-press-office/2011/01/14/statement-president-events-tunisia.

${ }^{44}$ http://www.whitehouse.gov/the-press-office/2011/10/07/remarks-president-obama-and-prime-minister-essebsiafter-bilateral-meeti.

${ }^{45}$ Mubarak ya era mencionado en este sentido en Bush y Scowcroft, op.cit., p. 61. Traub, op.cit., pp. 153-171.

${ }^{46}$ Mann, op.cit., pp. 255-269.
} 
segundo de estos discursos cuando ya Mubarak ha renunciado, apoya la puesta en marcha de la transición y el camino a unas elecciones, defendiendo la convivencia entre religiones y reconociendo la dificultad del proceso y el apoyo estadounidense. ${ }^{47}$

El apoyo inicial, con el paso del tiempo, quedaría diluido a raíz de los sucesivos y convulsos acontecimientos que se irían produciendo en Egipto. El asalto a la embajada de Israel, el control de los grupos yihadistas en el Sinaí o los desencuentros entre el ejército y la hermandad musulmana tras la victoria de Morsi, hasta el punto de que en octubre de 2012, en una conocida cadena de televisión en español, el presidente Obama llegaría a referirse al nuevo régimen egipcio diciendo que "no es un aliado pero tampoco un enemigo". "48 Actitud que acabaría culminando con la aceptación del golpe de Estado producido en julio de 2013 pero al que los líderes occidentales no se refirieron como tal dadas su posibles implicacionespor el ejército tras las protestas contra Morsi, que dio lugar a su detención y el nombramiento de un gobierno interino, que recabaría el apoyo de Estados Unidos con la visita del enviado estadounidense Bill Burns y de la Unión Europea con la visita de Catherine Ashton. ${ }^{49} \mathrm{La}$ dirigente europea, pronto se ocuparía de mediar entre las partes en conflicto, en medio de las acusaciones de los hermanos musulmanes de presiones para la aceptación del golpe militar. ${ }^{50}$

Con el paso del tiempo, la ilegalización y represión de los hermanos musulmanes por parte del ejército conduciría a unas elecciones presidenciales de 3 de junio de 2014 con baja participación en las que, de nuevo, un militar como es el general al Sisi volvería a la jefatura del Estado con el apoyo de actores regionales como Arabia Saudita o Emiratos Árabes Unidos y la aquiescencia occidental, como demostraría el restablecimiento de la cooperación militar con Estados Unidos, parcialmente suspendida tras el golpe de Estado, con uno de los actores clave del equilibrio regional. ${ }^{51}$

Probablemente el caso de mayor relevancia y el único en el que se produciría una intervención militar estadounidense fue el caso de Libia. La represión del régimen de Gadafi de las protestas, llevó pronto al desencadenamiento de una Guerra Civil y al establecimiento de una zona de exclusión aérea con la abstención en el Consejo de Seguridad de Naciones Unidas de los BRIC y Alemania con una resolución 1973, que autorizaba "tomar todas las medidas necesarias" para acabar con el supuesto genocidio. ${ }^{52}$ En realidad, la iniciativa de participar en este conflicto fue europea, con Sarkozy en una posición destacada. El presidente Obama había optado por una actitud prudente de manera inicial apoyando la posición de Gates, Donilon y Brennan, según su costumbre. Sin embargo, la petición de apoyo por parte de Cameron y Sarkozy -a su vez influido por el ensayista francés Bernard Henri-Levy-, argumentando el apoyo en guerras impopulares como Afganistán, junto con la presión de Clinton -que de manera inusual cambió de bando en el debate- que se alineó con las liberales intervencionistas Susan Rice y Samantha Power, acabaron haciendo que Obama cambiase de opinión en una alteración de los equilibrios tradicionales del proceso de toma de decisiones interno. Como resultado de dicha derrota en el debate a una intervención a la que se opuso de

\footnotetext{
${ }^{47}$ Véase http://www.whitehouse.gov/the-press-office/2011/01/28/remarks-president-situation-egypt y http://www.whitehouse.gov/the-press-office/2011/02/11/remarks-president-egypt

48 "Disputes Between Morsi, Military, Led to Egypt Coup", ABC News, 17 de julio de 2013. "Mohamed Morsi warns US it needs to change Middle East Policy", Daily Telegraph, 23 de septiembre de 2012.

49 "EU's Ashton on surprise visit to Egypt for talks with new regime", Al-Arabiya, 17 de julio de 2013.

50 "El gobierno egipcio ordena poner fin a la protesta islamista", El País, 1 de agosto de 2013.

51 "Sisi says Muslim Brotherhood will not exist under his reign", The Guardian, 6 de mayo de 2014. "EEUU reanuda la ayuda militar a El Cairo", El País, 28 de mayo de 2014. "Egypt declares el-Sisi winner of presidential election", CNN, 4 de junio de 2014.

${ }^{52}$ Recogida en http://www.un.org/es/comun/docs/?symbol=s/res/1973\%20 (2011).
} 
manera firme, el propio Gates afirma que estuvo dispuesto a dimitir y que no lo hizo debido a la cercanía del final de su labor como secretario de Defensa. ${ }^{53}$

A la hora de justificar la intervención y en su famoso discurso de 28 de marzo de 2011, los dos argumentos principales fueron la necesidad de impedir que la represión de Gadafi hiciese que el resto de dictadores se mantuviesen por la fuerza e impedir el genocidio. Rechazando las críticas de que no se pudiese intervenir en cualquier lugar, también rechaza la posibilidad de no intervenir nunca y que no siempre los intereses vitales o de seguridad pudiesen justificar la actuación dada su inexistencia en el caso libio. De igual modo y teniendo en cuenta lo sucedido en Afganistán e Irak, rechazaría tanto la presencia de tropas sobre el terreno como, supuestamente, la posibilidad de un cambio de régimen. Estos argumentos son confirmados en una carta escrita a los medios junto con Cameron o Sarkozy. Dichas justificaciones aparecen recogidas, además, en un contexto de cierta impopularidad de un nuevo conflicto, asociado a tropas estadounidenses en un Estado musulmán, tal y como se recoge en diversas encuestas. ${ }^{54}$

Lo más interesante y contradictorio del caso es que, siendo particularmente contrario en discurso y hechos a cambios de régimen como el que la Administración Bush había producido en Irak, la idea de mencionar "todas las medidas necesarias" y de provocar el cambio de régimen para impedir el supuesto genocidio, fue suya según Mann. ${ }^{55}$ Esta intervención daría lugar a un interesante debate en el que realistas y liberales intervencionistas se verían envueltos y donde las evocaciones a Irak salieron nuevamente a relucir por sus detractores y a Srebrenica o Ruanda por sus defensores. Autores tan relevantes como Richard Haass, Michael Scheuer, Michael Walzer, Stephen M. Walt, Michael Doyle, James Dobbins o Stewart Patrick participaron en torno a sus diferentes dimensiones sobre lo acertado o justo de la intervención o la posibilidad de poner "botas sobre el terreno". ${ }^{56}$ Pese a todo, el presidente estadounidense dejó la iniciativa a los europeos y limitó la presencia estadounidense a las primeras semanas del conflicto en lo que un miembro de la Administración definiría desafortunadamente "liderando desde detrás" Leading from Behind. ${ }^{57}$

Tras casi seis meses de guerra se produjo la ejecución de Gadafi, que planteó ciertas dudas sobre las credenciales democráticas de los líderes rebeldes a los que se había estado apoyando, aunque Obama lo consideró una oportunidad para construir una "Libia democrática" 58 y después de grandes críticas, como las que el secretario de Defensa dedicó

\footnotetext{
53 "By his Own Reckoning, One Man Made Libya a French Cause", The New York Times, 1 de abril de 2011. “Obama Takes Hard Line With Libya After Shift by Clinton”, The New York times, 18 de marzo de 2011. Gates, op.cit., p. 522.

${ }^{54}$ http://www.whitehouse.gov/the-press-office/2011/03/28/remarks-president-address-nation-libya Cameron, David; Obama, Barack H. y Sarkozy, Nicolás: "Libya's Pathway to Peace", The New York Times, 14 de abril de 2011. http://www.gallup.com/poll/148196/americans-shift-negative-view-libya-military-action.aspx.

${ }_{55}$ Mann, op.cit. pp. xi-xx y 281-301.

${ }^{56}$ Dobbins James F.: "Libya Nation-Building After Qaddafi. Helping the Rebels Help Themselves", Foreign Affairs, 23 de Agosto de 2011. Doyle, Michael W.:"The Folly of Protection. Is Intervention Against Qaddafi's Regime Legal and Legitimate?", Foreign Affairs, 20 de marzo de 2011. Haass, Richard N.: “The U.S. Should Keep Out of Libya", The Wall Street Journal, 8 de marzo de 2011. Patrick, Stewart: "Libya and the Future of Humanitarian Interventions. How Qaddafi's Fall Vindicated Obama and RtoP”, Foreign Affairs, 26 de Agosto de 2011. Scheuer, Michael: “The Zawahiri Era”, The National Interest, $\mathrm{n}^{\circ} 115$ (septiembre/octubre 2011), pp. 2325. Walt, Stephen M.: "What Intervention in Libya tell us about the neocon-liberal alliance", Foreign Policy, 21 de marzo de 2011.

Walzer, Michael: “The Case Against Our Attack on Libya”, The New Republic, 20 de marzo de 2011.

57 Chesterman, Simon: "Leading From Behind: The Responsibility to Protect, the Obama Doctrine, and Humanitarian Intervention After Libya”, New York University Public Law and Legal Theory Working Papers, Paper 282 (1 de junio de 2011).

58 http://www.whitehouse.gov/the-press-office/2011/10/20/remarks-president-death-muammar-qaddafi
} 
en su discurso de despedida a los aliados europeos por su falta de inversión en Defensa, el cambio de régimen se consumó. ${ }^{59}$ No obstante, la labor de Nation-Building se dejaría en manos de los libios, fiel a la consigna de Obama de no verse envuelto en este tipo de actividad tras conflictos como los de Irak o Afganistán -Nation-Building at Home- y priorizar cuestiones internas. ${ }^{60}$

Con todo, el caso libio seguiría coleando durante mucho tiempo con consecuencias negativas para la Administración Obama. Las protestas de los republicanos por no haber sido consultados a la hora de intervenir primero y el asesinato del embajador Stevens condenado en un discurso por el presidente estadounidense después ${ }^{61}$, pondría en una difícil situación a la Administración frente a los republicanos, arruinando la posibilidad de Susan Rice de ser secretaria de Estado. De igual modo, los eventos en Malí mostrarían las consecuencias de una intervención que acabaría teniendo repercusiones negativas en la seguridad y estabilidad del Sahel. Por otro lado, las potencias emergentes y en particular Rusia y China, sintiéndose ultrajadas al ejecutarse un cambio de régimen cuando se había aprobado una zona de exclusión aérea, bloquearían ulteriores intentos de participación en conflictos como Siria, distanciándose de los líderes occidentales y llegándose a afirmar en el caso de Vladimir Putin, que Rusia utilizaría en lo sucesivo el derecho de veto para impedir que Occidente provoque "cambios de régimen" en Estados que le resulten incómodos. ${ }^{62}$

Los supuestos de Baréin, Siria o Yemen ilustran de manera adecuada las contradicciones de la política estadounidense y la ausencia de una estrategia regional clara. $\mathrm{Si}$ en el caso de Yemen, la Administración Obama presionó para lograr la salida del presidente al Saleh del país, en un contexto de crecimiento de la inestabilidad, presencia de al-Qaeda y de los ataques con aviones no tripulados o crecimiento del separatismo. En Baréin, donde los intereses de seguridad de las monarquías del Golfo y de Irán confluyen y donde la quinta flota estadounidense tiene su base, las protestas de la mayoría chií no lograron más que un respaldo verbal y relativo del gobierno estadounidense, incluso en aquellos momentos en los que Arabia Saudita y otros emiratos del Golfo enviaban tropas para sofocar la rebelión en paralelo a la preparación de la intervención en Libia, aplicando un doble estándar que no ha escapado a determinados analistas. ${ }^{63}$

Distinto ha sido el caso de Siria. A diferencia de Libia, Siria posee aliados regionales y en el Consejo de Seguridad como es el caso de Irán o de Rusia, que como es bien sabido posee su base de Tartus en dicho Estado. Como Sanger manifestó de manera ingeniosa, "Rusia no estaba más dispuesta a dejar caer a Asad que Estados Unidos al rey de Baréin". ${ }^{64} \mathrm{Si}$ bien en sus primeros años de mandato la Administración Obama trató de limar asperezas con un adversario tradicional de Estados Unidos e Israel en la región, la represión de las protestas condujo inicialmente a una petición de que Asad liderase una transición en el país y luego se

\footnotetext{
${ }^{59}$ Recogido en http://www.defense.gov/speeches/speech.aspx?speechid=1581.

${ }^{60} \mathrm{http}: / /$ www.whitehouse.gov/the-press-office/2011/06/25/weekly-address-strengthening-america-investinghome.

${ }^{61}$ Glennon, Michael J. (2011): "The cost of "Empty Words". A Comment on the Justice Department Libya's Opinion", Harvard National Security Journal Forum, pp. 1-19. Ver: http://www.whitehouse.gov/the-pressoffice/2012/09/12/remarks-president-deaths-us-embassy-staff-libya

62 "Susan Rice withdraws from consideration as secretary of State", CNN, 14 de diciembre de 2012. "Loothed Lybian Arms in Mali May Have Shifted Conflict's Path", The New York Times, 7 de febrero de 2013. "Putin's Russia set against regyme change in Syria", Reuters, 28 de enero de 2012.

63 “Amid uprising, Yemen president quits after 33 years", NBC News, 23 de noviembre de 2011. Massimino, Elisa: "An intolerable status quo in Bahrein", The Washington Post, 2 de diciembre de 2011. Ignatius, David: "High Stakes over Bahrein", The Washington Post, 15 de marzo de 2011.

${ }^{64}$ Sanger, David E. (2013): Confront and Conceal. Obama's Secret Wars and Surprising Use of American Power, Nueva York, Broadway Paperbacks, pp. 358-366.
} 
retirase y, a continuación, pedir su salida del poder y apoyar de manera explícita a la oposición -que por su composición no necesariamente despierta simpatías entre todos los miembros de la Administración y muchos de sus aliados- tanto diplomáticamente como con el envío de armamento, que algunos de sus aliados regionales ya estaban haciendo llegar. La cuestión de armar o no a los rebeldes sirios suscitaría una enorme controversia interna dentro de la Administración Obama, con Hillary Clinton defendiendo la idea de armar a los rebeldes frente a la posición original del presidente. Esta discrepancia sobre la cuestión siria, sería aireada con posterioridad en los medios merced a algunas declaraciones de la ex secretaria de Estado. Las fuertes discrepancias con Rusia en este caso y después de la intervención en Libia, sin embargo, impidieron que se produjese una intervención amparada por Naciones Unidas ante la reiterada oposición tanto de Rusia como de China. ${ }^{65}$

Los acontecimientos en Siria han servido de manera destacada para re-configurar la política exterior estadounidense hacia la región. Si en agosto de 2012 y ante las intensas presiones internas -por neoconservadores y liberales intervencionistas- y externas -Arabia Saudita e Israel- el presidente estadounidense fijo una línea roja que "podía modificar sus cálculos". Esta no era sino la posible utilización de armas químicas por parte del régimen de Asad para reprimir a su pueblo. Cuando en agosto de 2013 un supuesto ataque con armas químicas se produce contra un suburbio de Damasco controlado por los rebeldes, estalla una crisis internacional que a punto estaría de provocar una intervención "limitada" de varios días contra el régimen. ${ }^{66}$

Los elevados costes y riesgos de una intervención que afrontaba una intensa oposición por parte de la opinión pública estadounidense, dividió a la Liga Árabe y al Consejo de Seguridad de Naciones Unidas, fue rechazada por el parlamento británico y generó una tremenda controversia dentro de la Administración Obama -que internamente se había deslizado desde la posición de si armar o no a los rebeldes hasta cómo hacerlo-. Los choques entre figuras como Samantha Power y el jefe de gabinete del presidente Dennis McDonnough fueron constantes y el propio presidente pedía modificar de manera continuada a sus asesores militares los planes establecidos para la intervención. En esta ocasión y a diferencia de lo que sucedió con el caso libio, la posición de Power no triunfó en el debate interno de la Administración y ante las dudas y el único apoyo decidido de Francia a participar en la operación, el presidente remite la decisión al Congreso Estadounidense. ${ }^{67}$

\footnotetext{
${ }^{65}$ Tal y como puede verse en http://www.whitehouse.gov/the-press-office/2011/08/18/statement-presidentobama-situation-syria y

http://www.whitehouse.gov/the-press-office/2012/02/04/statement-president-syria. "Rusia y China vetan de nuevo la condena a Siria en el Consejo de Seguridad", El país, 19 de julio de 2012. "Congressional panels approve arms aid to Syrian Opposition”, The Washington Post, 22 de Julio de 2013. Clinton, op.cit., pp. 460464.

${ }^{66}$ Kessler, Glenn: "President Obama and the red Line on Syria's chemical weapons", The Washington Post, 6 de septiembre de 2013. "Off-the-Cuff Obama Line Put the U.S.in Bind on Syria", The New York Times, 4 de mayo de 2013. "La oposición denuncia cientos de muertos por gas nervioso en Siria", El País, 21 de agosto de 2013. "U.S. set for Syria strike after Kerry says evidence of chemical attacks is clear", The Guardian, 31 de Agosto de 2013.

${ }^{67}$ Sanger, op.cit., p. 432. Haass, op.cit. "Syria Crisis: Cameron loses Commons vote on Syria action", $B B C$ News, 30 de agosto de 2013. "France's Hollande Backs US on Syria Action", BBC News, 30 de Agosto de 2013. Farwell, James P.: "Syria: Let the Locals Lead", The National Interest, 22 de noviembre de 2013. Obama's Uncertain Path Amid Syria Bloodshed", The New York Times, 22 de octubre de 2013. A modo de ejemplo véase la encuesta en perspectiva comparada elaborada por Gallup en http://www.gallup.com/poll/164282/supportsyria-action-lower-past-conflicts.aspx. "Obama wants Congress's okay for Syria strike" The Washington Post, 31 de agosto de 2013. Moret, Vicente: "Parlamentos y guerra", Política Exterior, vol. XXVIII, n 156 (noviembre/diciembre 2013), pp. 138-145.
} 
El Congreso probaría estar tan dividido como la Administración y muy condicionado por la oposición de la opinión pública. Tanto el Senado como la Cámara de Representantes se dividieron, así como los propios partidos. En el caso del Partido Republicano destacaría la oposición de Rand Paul frente a la postura sostenida por John McCain o Lindsey Graham. En esta situación Rusia aprovecharía un comentario del secretario de Estado John Kerry -uno de los grandes defensores de la intervención- para ofrecer una salida diplomática a la posible intervención, con la entrega del arsenal químico sirio a fuerzas internacionales para su destrucción y abrir el diálogo entre el régimen y la oposición en la fallida Conferencia de Ginebra. Esta solución diplomática, con el paso del tiempo mostraría ser un éxito para un régimen que ha obtenido de manera reciente ciertos avances en el campo de batalla frente a una dividida oposición -pese al apoyo recibido de actores como arabia saudita, Catar o Turquía- en la que los grupos moderados se ven condicionados, y en ocasiones enfrentados, a la posición más radical de los grupos yihadistas que lo integran como al-Nusra y, sobretodo, el Estado Islámico en Irak y Levante. Asad, en cambio, ha podido beneficiarse del apoyo decidido de Rusia, Irán o la milicia Hezbolá e incluso se ha permitido celebrar unas cuestionadas elecciones presidenciales a efectos de legitimar su poder. El supuesto sirio, por otro lado, generaría un enorme debate sobre las dudas que el liderazgo de un presidente estadounidense, que no hacía cumplir sus propias líneas rojas, despertaba. ${ }^{68}$

La solución diplomática del caso sirio, conjuntamente con las negociaciones nucleares llevadas a cabo con un importante actor regional como es Irán desde la llegada al poder del presidente Rouhani, sin embargo, han permitido volver a marcar un cambio en la política exterior de la Administración o, si se quiere, un retorno a los orígenes de la misma. Si los inicios de la "Primavera Árabe" dieron lugar a discursos y evocaciones wilsonianas, materializada sobretodo pero no únicamente en la intervención libia. La creciente inestabilidad e incertidumbre regional han marcado el retorno a una política exterior realista materializada en discursos del presidente estadounidense como el que lanzó en la Asamblea General de Naciones Unidas el 24 de septiembre de 2013 donde, si bien no deja de lado completamente la defensa de la democracia y los derechos humanos o pasadas acciones como la intervención en Libia, reconoce los límites de lo que Estados Unidos puede conseguir en lo que respecta a las transformaciones regionales. Asimismo, establecerá una nueva agenda regional que su propia consejera de Seguridad Nacional, Susan Rice, deberá seguir y que se concentra en la protección de una serie de intereses vitales o estratégicos como son la garantía del flujo energético, la lucha antiterrorista o evitar tanto la proliferación como el uso de armas de destrucción masiva y las agresiones externas como sucedió en la Guerra del Golfo. ${ }^{69}$

\footnotetext{
68 "Vote on Syria Sets Up Foreign Policy Clash Between 2 Wings of GOP", The New York Times, 2 de septiembre de 2013. "Obama Faces Barrier in His Own Party on Syria”, The New York Times, 4 de septiembre de 2013. "Split Senate Panel Approves Giving Obama Limited Authority on Syria”, The New York Times, 4 de septiembre de 2013. Golan-Vilella, Robert:" The Rand Paul Moment", The National Interest, 31 de enero de 2014, en http://nationalinterest.org/blog/the-buzz/the-rand-paul-moment-9796. Para el citado debate véase http://www.youtube.com/watch?v=H0YgZZOXuHg o Krauthammer, Charles: "The Fruits of Epic Incompetence", The Washington Post, 12 de septiembre de 2013. "Critics say Obama Syria's Deal with Putin Only Weakens U.S.; President Brushes Off "Style Points", The Washington Times, 15 de septiembre de 2013. Haass, Richard N.: “America Must Stick a Course on Syria”, Council on Foreign Relations, 2 de septiembre de 2013, en http://www.cfr.org/syria/america-must-stick-course-syria/p31324. Keck, Zachary: "America is Winning the Syria's Civil War, The National Interest, 28 de enero de 2014. "El Asad escenifica sus avances bélicos en las presidenciales sirias", El País, 2 de junio de 2014.

69 "Rice Offers a More Modest Strategy for the Mideast", The New York Times, 26 de octubre de 2013. El citado discurso puede verse en

http://www.whitehouse.gov/the-press-office/2013/09/24/remarks-president-obama-address-united-nationsgeneral-assembly.
} 
Este discurso, además, sería complementado por el más reciente lanzado en la Academia de West Point el 28 de mayo y que algunos analistas, de manera equivocada, han relacionado con una supuesta doctrina Obama. En dicho discurso el presidente se mostraba a sí mismo como un defensor del "excepcionalismo americano", definido de una manera un tanto peculiar como base del respeto al derecho y las instituciones internacionales. En su discurso llega a identificar las posiciones realistas e idealistas o "intervencionistas" y a exponer los cuatro pilares del liderazgo estadounidense, de los cuales si bien resalta la importancia de la transparencia y los derechos humanos y la democracia como tercer y cuarto pilar, cabe destacar la importancia de los dos primeros. En ellos expone su concepción del uso de la fuerza, unilateral, si es necesario a la hora de defender intereses vitales y multilateral, en otros casos, como aquellas intervenciones fundamentadas en concepciones morales. Su defensa del excepcionalismo no le obsta para reconocer que el uso de la fuerza militar no lo resuelve todo. En la práctica el presidente estadounidense parece haber elegido de las dos opciones expuestas en política exterior por la primera, vinculada al realismo y ejemplificándola en la figura del presidente Eisenhower. ${ }^{70}$

\section{Conclusiones}

Tal y como hemos podido observar, la política exterior de la Administración Obama hacia la región se ha ido modificando a lo largo del tiempo. Desde la intención original de buscar vías de reconciliación y diálogo con algunos de los regímenes afectados por la política de la Administración Bush y distanciarse de ésta, se pasó a apoyar de manera decidida los diferentes procesos de cambio que se iban produciendo en la región. En el discurso político, el presidente se distanció originalmente de las intenciones de su predecesor y, sobretodo, de los cambios de régimen por la fuerza y de los procesos de construcción estatal que tan caros habían resultado para la Administración Estadounidense. La intención de acercar la política estadounidense a las potencias emergentes y al Pacífico en detrimento de otras regiones como Europa, Latinoamérica o el Próximo Oriente marcaron ciertos cambios en la actitud original de la misma. Sin embargo este proyecto inicial no se pudo culminar con éxito y la "Primavera Árabe" fue una de las razones que contribuyeron a ello.

En un primer momento, la Administración Obama se veía afectada por la mala imagen de la política de su predecesor en el conjunto del mundo islámico, pero también a nivel general. Desde el principio existieron posturas tan diversas en su gabinete como las que sostuvieron el secretario de Defensa Robert Gates y la embajadora en Naciones Unidas Susan Rice pero en un origen la agenda wilsoniana de expansión de la democracia había tendido a ser dejada de lado en las votaciones, por un lado por el apoyo de Obama al sector realista de su Administración, pero también por la necesidad de distanciarse de ese idealismo wilsoniano que había dado tan malos réditos a la política estadounidense. No obstante, este idealismo nunca fue olvidado del todo pese a las advertencias de que no "impondría a nadie forma de gobierno alguna", que utilizó en el discurso de el Cairo al referirse a la cuestión de la democracia. De igual manera, la prioridad de combatir a al-Qaeda, que culminaría con la muerte de Ben Laden y de poner fin de manera relativamente dignas a los conflictos iraquí y afgano, fueron considerados los objetivos principales. Ni siquiera las protestas producidas en Irán hicieron que la Administración se plantease un apoyo claro a las mismas.

Esta política realista mayoritaria se impuso durante estos dos primeros años hasta el estallido de las primeras revueltas. Si Túnez no había planteado un problema de calado en lo

\footnotetext{
${ }^{70}$ Véase el citado discurso en http://www.whitehouse.gov/the-press-office/2014/05/28/remarks-president-westpoint-academy-commencement-ceremony.
} 
que respecta a los intereses vitales y estratégicos de la Administración, que no se vieron en exceso afectados por el cambio, distinta fue la cuestión en el caso de Mubarak en Egipto. Éste había sido un aliado durante mucho tiempo, que había permitido mantener con éxito una política de equilibrio regional que favorecía, no solo a los Estados occidentales, sino a algunos de sus aliados como Arabia Saudita o Israel. Las grandes cantidades de dinero que Estados Unidos ofrece a su ejército constituyen un elemento de gran influencia sobre una de las instituciones más importantes de aquel Estado. La potencial inestabilidad, junto con la concepción de un "statu quo insostenible" fueron algunas de las razones que convencieron a la Administración, no sin debate y polémica, a apoyar y presionar para obtener la renuncia de Mubarak, si bien los acontecimientos posteriores irían debilitando el apoyo a una transición truncada, por el momento, por un golpe de Estado, la ilegalización de los hermanos musulmanes y la victoria del general al Sisi.

El caso libio es uno de los más relevantes e interesantes a la hora de considerar una cierta ruptura en la política exterior de dicha Administración, al ser el único caso que devendría en una intervención militar que acabaría derrocando al régimen de Gadafi de manera similar a lo sucedido en el caso de Irak. Si bien la iniciativa en este caso fue francesa, la presión de algunos de los adversarios de Gadafi en la región, así como el temor a la consecución de un genocidio y de sus efectos en las transiciones de otros regímenes afectados por las revueltas, le hizo decidirse por la intervención. Sería uno de los pocos casos en los que el presidente alteró su comportamiento habitual, situándose en el mismo bando que los liberales intervencionistas, obteniendo una resolución que iba más allá de la zona de exclusión aérea y conseguir la expresión "utilizar todos los medios necesarios" que permitía una acción más enérgica pese a las protestas de China o Rusia. El caso, además, despertó un enorme debate en un Estados Unidos ya afectado por los eventos en Afganistán e Irak y convirtió, de nuevo, a los realistas que le habían apoyado inicialmente en críticos de la Administración, como fue el caso destacado de Brent Scowcroft o del propio Gates.

No en todos los casos la ideología liberal tuvo una importancia tan destacada como en Libia. Esta política, a menudo se ha visto afectada por enormes contradicciones y dobles estándares en el apoyo a las reformas y el caso de la península arábiga es el más destacado. Si en Yemen, en medio de una considerable crisis, las presiones de la Administración tuvieron cierto éxito al lograr la renuncia del presidente Saleh, en Baréin la represión de la dinastía reinante sobre la mayoría chií del Estado fue tratada con cierta comprensión o aquiescencia por la Administración Estadounidense, que no se pronunció de manera clara cuando las tropas saudíes entraron en el país y ayudaron a sofocar la revuelta ante la magnitud de los intereses estratégicos que tiene en el país. El apoyo a Estados autocráticos como Arabia Saudita, pese a las discrepancias en casos como Egipto, también se mantuvo intacto.

Finalmente, en el caso sirio, de manera parcial por el apoyo de aliados regionales o internacionales como Rusia o Irán, por la escasa ascendencia ante el régimen de Asad, las cuestionables credenciales democráticas de la oposición siria y el elevado coste que supondría una intervención militar en aquel Estado, impedirían una intervención directa pese al apoyo que ciertos miembros del Congreso Estadounidense, como Graham o McCain, han brindado. En estos últimos casos, la magnitud de los intereses vitales y la prudencia han predominado frente al caso libio, donde el elemento ideológico tuvo un mayor papel ante la ausencia de intereses de seguridad estadounidenses y del propio aislamiento de Gadafi.

Es preciso destacar que, pese a este apoyo inicial y a la creencia declarada en el elemento positivo de estos procesos de cambio. La actitud de la Administración se iría modificando con el paso del tiempo, para volver a mantener una cierta política de statu-quo, que acabaría superando la pasión original y el entusiasmo por la expansión de la democracia en la que, probablemente, el presidente estadounidense nunca creyó de manera incondicional. 
La creciente inestabilidad regional, la guerra civil siria convertida de manera parcial en un conflicto sectario, las difíciles relaciones con los gobiernos islamistas que, de manera paulatina y pese a las profecías de los defensores de la "Primavera Árabe" iban ganado en una elección tras otra, el golpe de Estado en Egipto y los propios intereses de seguridad, harían que la antigua política realista volviera de nuevo a su curso.

A pesar de que algunos autores como Mann, parecen haber considerado la "Primavera Árabe" como un cierto momento de ruptura, similar al que la fallida operación en Somalia o el 11 de Septiembre había producido en las Administraciones de Clinton o Bush hijo, parece que el tiempo ha hecho desmentir este planteamiento. El transcurso de los acontecimientos ha ido mostrando que caso como el de Libia han sido considerados más una excepción que una regla de comportamiento dentro de dicha Administración. Estados Unidos, al igual que la UE, parecen haber aceptado sin demasiados problemas el golpe de Estado que acabó con el presidente Mursi, se han mostrado renuentes a realizar un apoyo directo y decidido a la oposición siria y han mantenido el apoyo a los gobiernos autocráticos con los que siempre mantuvieron buenas relaciones. El relato positivo de los hechos no parece haber hecho mella en la política de la Administración Estadounidense a la región en estos casos.

$\mathrm{Ni}$ siquiera, quitando la relevante excepción libia, ha alterado el "equilibrio ideológico" de la Administración Estadounidense, en el que los realistas han llevado tradicionalmente la voz cantante, apoyados por el propio Obama. En casos posteriores y relevantes como Baréin o Siria, hasta el momento, los liberales intervencionistas como Rice o Power no han conseguido el éxito que tuvieron a la hora de preconizar la intervención en Libia. Todo ello a pesar de algunos de los cambios producidos dentro de la Administración, con la incorporación de Chuck Hagel al Pentágono y la de Susan Rice al Consejo de Seguridad Nacional tras la retirada de Donilon o de Samantha Power a Naciones Unidas. Hasta el momento, el presidente estadounidense no ha mostrado un excesivo entusiasmo por cambios radicales en un entramado de toma de decisiones, donde él siempre ha sido el que ha llevado la voz cantante. El Kissinger de Obama, como un analista ha citado de manera ingeniosa, es el propio Obama.

Esta política exterior, no coherente, repleta de contradicciones y dobles estándares, no puede ser calificada con adjetivo alguno. Como la propia política, se adapta a los acontecimientos, los intereses, los matices y los hechos de cada Estado y lugar concreto haciendo que la Administración actúe de manera distinta, respondiendo a las exigencias de la propia realidad política que, posiblemente un Morgenthau o un Kennan, salvando casos como el de Libia, podrían haber considerado acertada. Esto es perfectamente coherente con la doctrina -o no doctrina- de un presidente estadounidense que nunca ha definido una estrategia única y clara como forma de actuar en política exterior. Si la doctrina Obama consiste en no tener doctrina, y Obama no tiene doctrina "por no ser doctrinario", esta es precisamente la política que cabe esperar del presidente estadounidense en una región que se ha acabado convirtiendo en el principal campo de batalla de los diferentes grupos ideológicos que forman parte del paisaje de la política exterior estadounidense.

Esto sin embargo no obsta con reconocer las posibles ventajas de disponer de una doctrina o estrategia ${ }^{71}$ a efectos de hacer frente a los diferentes desafíos y la consecución de los objetivos planteados en un momento particularmente convulso, aún con las dificultades planteadas por la ausencia de un enemigo estatal que supongo una amenaza sistémica, al menos en esta región del globo. Este es, indudablemente, el punto más débil de la estrategia

\footnotetext{
${ }^{71}$ Es necesario reconocer, en cualquier caso, la distinción conceptual entre estrategia y doctrina, entendiendo la segunda como un conjunto de convicciones que sirven de base para la acción política y siendo la segunda mucho más concreta que la primera.
} 
defendida por el presidente estadounidense pues esta planificación permitiría afrontar y planificar de una manera más adecuada la defensa de los objetivos estratégicos y de los intereses vitales a los que el presidente estadounidense ha situado como centro de la política exterior regional.

La opción recogida en los discursos de Naciones Unidas y West Point es ampliamente coincidente con la visión planteada en este artículo. Tal y como el presidente estadounidense reconoce, la potencia norteamericana se enfrente a una serie de desafíos regionales de naturaleza muy diversa que van desde las negociaciones en torno al plan nuclear iraní hasta combatir a los diferentes grupos terroristas, pasando por garantizar el flujo energético o, aún sin mencionarlo expresamente, contrarrestar la creciente influencia de actores como China y recuperar la "dañada" confianza de otros como Arabia Saudita o Israel. Es una política de marcado signo realista que, sin embargo, se enfrenta con otro desafío adicional como es el de compaginar los crecientes intereses que la potencia norteamericana tiene en la región de AsiaPacífico, ejemplificado en el famoso "giro"72, con la de lograr la consecución de los objetivos estratégicos y los intereses vitales que Estados Unidos tiene y tendrá en un futuro cercano en el Próximo Oriente. ${ }^{73}$

Esta política no ha quedado exenta de dudas y riesgos. La reciente reapertura del sempiterno conflicto entre israelíes y palestinos durante 50 días en Gaza que ha llevado a casi 2200 muertos en ambas partes a pesar de los esfuerzos estadounidenses por lograr un arreglo diplomático y está todavía pendiente de una resolución, siquiera temporal, ha desembocado en una tensión relativa con uno de sus aliados regionales más cercanos como es Israel y, de manera previsible, seguirá generando problemas aún cuando hoy en día no es ya el principal foco de inestabilidad regional. ${ }^{74}$

Más relevantes son los acontecimientos en Irak. En uno de los países que no ha formado parte de la "Primavera Árabe", como es el caso de Irak, la creciente inestabilidad producida desde que en diciembre de 2011 las tropas estadounidenses abandonasen dicho país, conjuntamente con la "incompetencia" atribuida al primer ministro Nuri al-Maliki y el descontento de la población suní ,han generado un caldo de cultivo que ha permitido un recrudecimiento de las actividades terroristas y, a la postre, el fortalecimiento del Estado Islámico en Irak y Siria. Esta organización terrorista ha llegado a poner en evidencia con la conquista de varias ciudades del norte del país, la fortaleza de un ejecutivo central necesitado todavía de apoyos exteriores y con una legitimidad interna cuestionada por los grupos étnicos y/o religiosos minoritarios y obligado a que Estados Unidos deba replantear su estrategia para no poner en riesgo todo lo conseguido hasta ese momento. Además ha llevado a situaciones impensables a corto plazo como una negociación abierta con Irán para reconducir la situación en Irak, reconocida como necesaria incluso por destacados líderes políticos vinculados a posiciones neoconservadoras como es el senador Lindsey Graham. ${ }^{75}$

El reciente anuncio del presidente estadounidense de bombardeos selectivos al ISIL en apoyo de las milicias kurdas sobre la base de la protección de la población civil y la necesidad de detener su avance -con las cautelas observadas en recientes pronunciamientos y la defensa

\footnotetext{
${ }^{72}$ Una de las razones aducidas para el famoso giro es la del mayor equilibrio existente en el cálculo costebeneficio, esto es, entre los costes de la presencia estadounidense en dicha región y los potenciales beneficios a obtener de la misma.

${ }^{73}$ Es interesante leer a este respect a Pollack, Kenneth M. y Takeyh, Ray: "Near Eastern Promises. Why Whashington should Focus on the Middle East", Foreign Affairs, vol. 93, no 3 (mayo/junio 2014), pp. 92-105.

74 “Quién es el vencedor de la "guerra de los 50 días” entre Israel y Hamas”, El Mundo, 27 de agosto de 2014. "Las tensiones entre Estados Unidos e Israel, querellas de familia”, El País, 18 de agosto de 2014.

75 "Los yihadistas toman Mosul y llevan el caos a Irak", El Mundo, 10 de junio de 2014. "U.S. Open to Talks with Iran over Iraq", The Washington Post, 16 de junio de 2014.
} 
de que este conflicto ha de tener una solución iraquí-, el estudio de posibles acciones similares en Siria contra esta organización o el apoyo al nombramiento de Haidar al Abadi como primer ministro, han vuelto a poner de manifiesto la fragilidad de lo logrado y la imposibilidad de distanciarse de una región que aún conserva intereses de seguridad notables para la potencia norteamericana en un momento en que el este europeo y Asia Oriental demandan una mayor atención. $^{76}$

Hasta el momento el presidente estadounidense no ha logrado desarrollar una estrategia satisfactoria -originalmente planteó que "aún no tenía una estrategia" para combatir al ISIL en Siria-, lo que ha llevado a acusaciones de exceso de "prudencia" por parte de su ex secretaria de Estado Clinton y solo de manera muy reciente, tras la Cumbre de la OTAN en Cardiff se ha comenzado a montar una coalición de, al menos diez aliados occidentales a los que se añadirían algunos Estados árabes que colaborarían de manera diversa. La decisión estadounidense de no favorecer a Asad en ningún caso, optando en cambio por el entrenamiento de los miembros del Ejército Libre Sirio y el ambiguo rol de Irán, también introducen enormes incertidumbres en la situación siria que no ayudan precisamente a combatir la amenaza para la seguridad regional e incluso occidental que el ISIL supone. En el fondo, las críticas tanto de Clinton como de destacados neoconservadores como Elliott Abrams, llevan a un nuevo debate ideológico sobre la naturaleza de la política exterior estadounidense debido a las dudas que la política del presidente Obama despierta. El presidente estadounidense, que en una reciente entrevista ha considerado que armar a una oposición no profesional, dividida y fragmentada nunca fue una opción real se ve, sin embargo, amparado en el caso sirio porque las opciones defendidas por neoconservadores o liberales intervencionistas, materializadas en las Guerras de Irak de 2003 y -pese a la propia posición del presidente estadounidense de manera pública y como responsable último- de Libia en 2011, no pueden considerarse en modo alguno un modelo de éxito. ${ }^{77}$

Partiendo de la base de la imposibilidad de la inexistencia de crítica alguna, como el caso iraquí ha demostrado. Cualquier estrategia surgida de la Administración, deberá afrontar riesgos y situaciones extraordinariamente complejas en un escenario regional de enorme inestabilidad, con la clara conciencia de los que objetivos a cumplir siempre serán limitados y, a menudo, el objetivo principal no deberá ser tanto como conseguir su cumplimiento de manera efectiva, sino de manera relativa, ocasionando el menor daño posible. Si esto se cumple este puede ser, probablemente, el mayor éxito de la visión expuesta por el presidente estadounidense, que debería ayudar de manera limitada y dentro de las opciones posibles, a reconducir una región en proceso de cambio que se encuentra en una situación incierta.

\footnotetext{
76 http://www.whitehouse.gov/the-press-office/2014/08/07/statement-president y "Estados Unidos muestra su apoyo a Haidar al Abadi como nuevo primer ministro de Irak", $A B C, 12$ de agosto de 2014.

77 "Estados Unidos forma una alianza de 10 países para combatir a los yihadistas", El País, 5 de septiembre de 2014. "EEUU logra apoyo de países árabes en su campaña contra el Estado Islámico", Reuters, 11 de septiembre de 2014. En lo que respecta al debate ideológico véase entre otras muchas noticias sobre el debate de la política exterior reciente de la Administración "Obama on the World. President Obama Talks to Thomas L. Friedman About Iraq, Putin and Israel", The New York Times, 8 de agosto de 2014. "Hillary Clinton: 'Failure' to Help Syrian Rebels Led to the Rise of Isil", The Atlantic, 10 de agosto de 2014. "Ten Obama Press Conference Lowlights" The Washington Post, 29 de agosto de 2014. Abrams, Elliott: "The Man Who Broke the Middle East", Politico, 22 de junio de 2014.
} 